\title{
Adolescence-Sexual Behaviour as a Correlates of Academic Performance on Agricultural Science in Ibadan North Local Government Area
}

\author{
Adeniyi, O. A. ${ }^{1}$, Amao, S. A. ${ }^{2}$, Ifegwu, K. U. ${ }^{1}$ and Olapade-ogunwole, F. \\ ${ }^{I}$ Department of Agricultural Economics, Ladoke Akintola University of Technology, P. M. B 4000, Ogbomoso, \\ Nigeria. \\ ${ }^{2}$ Departments of Agricultural Technology, Oyo State College of Agriculture, Igboora, Oyo State, Nigeria.
}

\begin{abstract}
This study evaluated adolescence-sexual behaviour as a correlates of academic performance on agricultural science in Ibadan North Local Government Area. Multistage sampling procedure was employed for sampling of respondents for the study. Primary data were obtained from 150 respondents. Data were analyzed using descriptive statistics and Pearson's Product Moment Correlation Coefficient (PPMC). These were analyzed to determine the relationship between independent variables (socioeconomic and adolescence-sexual behaviour of the respondents) and the dependent variables (student performance in agricultural science). Mean age of the respondents was 15 years, $56.7 \%$ were females while $43.3 \%$ were males. The results of student performance revealed that, the mean score was $58.61 \%$ for agricultural science. The sexual intercourse status of respondents (INTERCOS) correlate with student academic performance in agricultural science subject and it is statistically significant at $1 \%$ level. The coefficient is also positive. Policy makers should employ counselors in all public secondary schools and mandate private secondary schools to do likewise.
\end{abstract}

Keywords: Adolescence, sexual intercourse, PPMC.

\section{Introduction}

The economy of most developing countries depends on agriculture. It is has played a very significant role in man's civilization. The importance of agriculture to the nation prompt our educationists and government to make provisions in the National Policy on Education for Practical Agriculture in the curriculum of the junior secondary school and Agricultural Science in the senior secondary school curriculum as core subjects (FGN, 1990). Despite efforts to promote agriculture in this wise, its impact is yet to be felt.

It is necessary to understand what adolescence is, and what age range it constitutes. The definition of an adolescent varies from country to country. However, the World Health Organization (WHO) defines the adolescent as being a person between the age of 10 and 19 years, while youths are defined as persons between the age of 15 and 24 years. Nigeria's adolescents has been defined as the age group between the ages of 10 and 24 years: this spans from the inception of puberty and ends in adulthood (FMOH and WHO, 1999; National Population Commission, 2003; Weyman, Watson, and Wetzel, 2004; Tripovic, 2004). This stage in human development has been recognized as having a unique bio-psychosocial impact on the individual (Formans and Emans, 2000; FMOH and WHO, 1999; National Population Commission, 2003; Weynan et al., 2004; Inem, Ayankogbe, Obazee, Ladipo, Udonwa and Odusote,, 2004). The adolescent population is increasing worldwide and presently constitutes one-fifth (1.2 billion) of the world population (FMOH and WHO, 1999). In Nigeria, adolescents constitute about $30 \%$ of the total population, according to estimates made in 2006 (National Population Commission, 2006).

Adolescence is a period of many transitions, which involves a process of confrontation with diverse tasks of development and with demands on development. It is a time of change, exploration, exuberance and youthful searching. Adolescents show marked changes in their social relationships sometimes leading to the breaking away from the family. Biologically, puberty occurs in response to changes in the body's hormone system. The hormonal stimulations on reproductive organs also stimulates behavioural changes such as being inquisitive about the growth and development of the body, experimenting with reproductive organs, sensitivity to appearance and body posture, aggressive tendency and increased conflict with parental values. This implies that though puberty has a biological foundation it also has social and psychological significance (Stattin and Magnusson, 1990).

In Nigeria, more than $60 \%$ of new HIV infections occur in youths ages 15 to 25 . This takes place against a background in which one third of the country's population of about 160 million are aged 10-24 years (NPC, 2007). Bracato (Cited in Oborio, 2010) reported that there is minimal access to proven sexuality, family life or HIV and AIDS education that would help them become sexually healthy adults practice safe sexual 
behavior, and reduce unintended pregnancy and Sexually Transmitted Diseases (STDs) including HIV. Forman (2003) noted that, a lack of information and a lack of voice continue to be primary causes of infection among the worst affected groups of women and youth adolescent and youth faced with multiple barriers to accessing reproductive and sexual health services and maintaining their reproductive health. These include lack of information and education, lack of youth-specific services, concern about confidentiality affordability and access to services social pressures and taboos.

The objectives of this study are to:

(i) examine adolescence-sexual behaviour of the respondents in the study area

(ii) describe academic performance in agricultural science and in other selected subject offered by the adolescence in the study area

(iii) analyze the correlate between adolescence sexual behaviour and their academic performance in agricultural science in the study area

Hypothesis of the Study:

$\mathrm{H}_{01}$ : $\quad$ Adolescence sexual behaviour of the respondents, do not have any significant effect on their academic performance in agricultural science.

\section{Methodology}

The study was conducted in Ibadan North Local Government of Oyo State, Nigeria. It is one of the Local Government Areas (LGA) in the urban areas of Ibadan Metropolis. It was founded by the Federal Military Government of Nigeria on 27th September 1991. It lies within longitude $8^{\circ} 5$ East of the Greenwich meridian and latitude $7^{\circ} 23^{\prime}$ North of equators (Ibor, Anjorin, Ita, Out and Bassey, 2011). According to the National Population Census (2006); it has a proportion of 306,763. The male population is given as 153,039 and female population as 153,756 . It is the largest local government in Ibadan with a land area of $145.58 \mathrm{~km}^{2}$ which is approximately $4.66 \%$ of the total land area of the city (Adenugha and Ijagbone, 2012). This area is a host to many educational centres in Nigeria. It has over 100 secondary school, more than 300 primary school, a polythechnic which is owned by Oyo State, and the University of Ibadan which is owned by Federal Government. This advantage puts Ibadan North Local Government Area ahead of other Local Government Areas in the aspect of educational facilities.

The data used were mainly primary: these were obtained through the use of a well-structured questionnaire and interview schedule. This was employed to make enquiries on socio-economic and adolescence sexual characteristics of the respondents. Multistage sampling procedure was employed for sampling of respondents for the study. The first stage involved the random sampling of three (3) secondary schools in Ibadan North Local Government Area of Oyo State. The second stage was the purposive sampling of Senior Secondary (SS) one and two classes. While, the third stage involved random sampling of students in these classes. Primary data were obtained from 150 respondents.

Descriptive statistics and Pearson's Product Moment Correlation Coefficient were employed. These were used as tools to analyse preferential characteristics and socioeconomic information of the individual and household selected for the survey. Pearson's Product Moment Correlation Coefficient (PPMC) computed the association between the independent variables [adolescence-sexual behaviour and socio-economic characteristics $\left(X_{n}\right)$ ] and dependent variable [student performance in agricultural science $(Y)$ ].

Where;

$Y=$ Student performance in Agricultural Science

$X_{n}=$ Explanatory variables; Adolescence and socio-economic characteristics

However,

For Sexual Behaviour;

$X_{n}=$ age, virginity, having sex intercourse, frequency of sex intercourse

Table 1: Definitions Of Abbreviation Used In The Analysis

\begin{tabular}{ll}
\hline Variables Abbreviations & Definitions \\
\hline AGE & Age of respondents \\
GEND & Sex of respondents \\
VIRGIN & Virginity of respondents \\
INTERCOS & Sexual intercourse status of respondents \\
INTERCOS_M & Number of sexual intercourse of respondents monthly \\
\hline
\end{tabular}

Source: Field Survey, 2013. 


\section{Results And Discussion}

Table 2 revealed the personal characteristics of respondents.

Age: Sixty percent of the respondents were within the range of age $12-15$ (years): while the minority were older older and they accounted for $40 \%$ of the respondents. The mean age of respondents was 15 years. These confirms the fact that, adolescence were interviewed in the study. It also indicate that pupils starts school early.

Years Spent in School: Over 55\% have 13 years schooling. This is an indication that over 55\% of the respondents were still in SS (Senior Schools) 1.

Sex: Majority (56.7\%) of the respondents were females: while the remaining $44.3 \%$ were males.

Religion: About $65 \%$ of the respondents were Christians: while the rest were Muslims.

Table 2: Personal Characteristics Of The Adolescence

\begin{tabular}{lll}
\hline Personal Characteristics & Frequency & Percentage \\
\hline Age (years) & & \\
$<12$ & 0 & 0.0 \\
$12-15$ & 90 & 60 \\
$16-19$ & 60 & 40 \\
Mean =15 years & & \\
Number of Years Spent in School & 83 & 55.3 \\
13 & 67 & 44.7 \\
14 & & \\
Sex & 65 & 43.3 \\
Male & 85 & 56.7 \\
Female & & 64.7 \\
Religion & 97 & 35.3 \\
Christianity & 53 & \\
Islamic & & \\
\hline
\end{tabular}

Source: Field survey, 2013.

Table 3 revealed the adolescence characteristics of respondents.

Virginity: About $33 \%$ of the respondents were not virgins. This reveals that government and other stakeholders in the educational sector have not been efficient in ensuring that the adolescence abstain from sexual intercourse.

Number of Lovers: Over $60 \%$ have lovers and the mean of number of lovers is 3 . This is an indication that the respondents have attraction to opposite sex.

Sexual Intercourse Status: Over 35\% of the respondents engaged in sexual intercourse. This is not acceptable for student at this level of age and education. It may lead to unwanted pregnancy, abortions and sexually transmitted diseases.

Frequency of Sexual Intercourse (Monthly): About 28\% of the respondents engaged in sexual intercourse between 1 to 5 times every month. This is an indication that these young folks has been negatively influenced.

Table 3: Adolescence Characteristics

\begin{tabular}{lll}
\hline Characteristics & Frequency & Percentage \\
\hline SEXUAL BEHAVIOUR & & \\
Virginity & 101 & 67.3 \\
Virgin & 90 & 32.7 \\
Not Virgin & & \\
Number of Lovers & 65 & 43.3 \\
No Lover & 55 & 36.7 \\
$1-5$ & 22 & 14.6 \\
$6-10$ & 4 & 2.7 \\
$11-15$ & 4 & 2.7 \\
$16-20$ & & \\
Mean=3 & 53 & 35.2 \\
Sexual Intercourse Status & 97 & 64.7 \\
Engaged & & \\
Not Engaged & & 64.7 \\
Frequency of Sexual & Intercourse & 28 \\
(Monthly) & 97 & 7.3 \\
Not Engaged & 42 & \\
$1-5$ & 11 & \\
$6-7$ & & \\
Mean $=1.48$, Maximum $=10$ & & \\
\hline
\end{tabular}

Source: Field survey, 2013.

Table 4 revealed the characteristics of student performance in agricultural science and other selected subjects. 
Agricultural Science: The mean score of $58.61 \%$ indicate that majority of the respondents perform above average. Biology: The mean score of $55.61 \%$ indicate that majority of the respondents perform above average.

Mathematics: The mean score of $54.61 \%$ indicate that majority of the respondents perform above average.

Table 4: Student Performance In Agricultural Science And Other Selected Subjects

\begin{tabular}{lcl}
\hline Characteristics & Frequency & Percentage \\
\hline Agricultural Science (\%) & 3 & 2 \\
$\leq 40$ & 40 & 30.7 \\
$41-50$ & 44 & 28 \\
$51-60$ & 37 & 23.3 \\
$61-70$ & 13 & 8 \\
$71-80$ & 13 & 8 \\
$\geq 81$ & 40 & \\
Mean $=58.61$, Maximum $=95$, Minimum & \\
Biology (\%) & 8 & 5.3 \\
$\leq 40$ & 42 & 28 \\
$41-50$ & 60 & 4 \\
$51-60$ & 20 & 13.4 \\
$61-70$ & 16 & 10.6 \\
$71-80$ & 4 & 2.7 \\
$\geq 81$ & & \\
Mean $=55.52$, Maximum $=87.5$, Minimum $=28$ & 6 \\
Mathematics (\%) & 9 & 40 \\
$\leq 40$ & 60 & 36 \\
$41-50$ & 54 & 10 \\
$51-60$ & 15 & 8 \\
$71-70$ & 12 & \\
Mean $=54.61$, Maximum = 87.5, Minimum $=35$ & \\
\hline
\end{tabular}

Source: Field survey, 2013.

Table 5 revealed the Pearson's Product Moment Correlation (PPMC) between adolescence-sexual behaviour and student performance in agricultural science. The sexual intercourse status of respondents (INTERCOS) correlate with student academic performance in agricultural science subject and it is statistically significant at $1 \%$ level. The coefficient is also positive. These implies that, student who engage in sexual intercourse still perform well in agricultural science. It also means that the result has $99 \%$ probability of accuracy while the $1 \%$ accounts for error term.

Table 5: Pearson's Product Moment Correlation Between Adolescence-Sexual Behaviour And Student Performance In Agricultural Science

\begin{tabular}{lllll}
\hline Variables & Sum of Squares & $\mathrm{r}$ - value & $\mathrm{p}$ - value & Remarks \\
\hline Sexual Behaviour & & & & \\
AGE & -303.473 & -0.113 & 0.167 & NS \\
VIRGIN & -32.727 & -0.037 & 0.656 & NS \\
INTERCOS & 209.153 & $0.230^{* *}$ & 0.005 & $\mathrm{~S}$ \\
INTERCOS_M & -280.680 & -0.0591 & 0.471 & NS \\
\hline
\end{tabular}

** $1 \%$ level of significance, $* 5 \%$ level of significance

Source: Field survey, 2013.

Table 5 revealed the Pearson's Product Moment Correlation (PPMC) between adolescence-sexual behaviour and student performance in agricultural science. Sexual Behaviour: The sexual intercourse status of respondents (INTERCOS) correlate with student academic performance in agricultural science subject and it is statistically significant at $1 \%$ level. Thus, the hypothesis that adolescence sexual behaviour do not significantly affect student performance in agricultural science is hereby rejected.

\section{Conclusions}

The maximum parents income was $\$ 500,000$ monthly: while the minimum was 25,000 . This result revealed that, there was very large gap between the poor and the rich, in the study. The results of student performance revealed that, the mean scores were $58.61 \%, 55.52 \%, 54.61 \%$ for agricultural science, biology and mathematics respectively. Pearson's Product Moment Correlation (PPMC) between adolescence-drug abuse and student performance in agricultural science. The sexual intercourse status of respondents (INTERCOS) correlate with student academic performance in agricultural science subject and it is statistically significant at $1 \%$ level. The coefficient is also positive. These implies that, student who engage in sexual intercourse still perform well in agricultural science. The hypotheses were stated in the null form. The hypothesis was that adolescence 
characteristics do not significantly affect student performance in agricultural science. Sexual intercourse status of respondents was significant at $1 \%$ level. Policy makers should employ counselors in all public secondary schools and mandate private secondary schools to do likewise. The counselors will be able to guard the students rightly on sensitive issues as sexual behaviour.

\section{References}

[1]. Adenugha, and I. O. Ijagbone, Correlates of Alcohol Consumption Among Adolescents in Ibadan North Local Area of Oyo State, Nigeria. ISSN 2039-2117 Mediterranean Journal of Social Sciences Vol. 3 (2) May 2012. Doi: 10.5901/mjss.2012.v3n2.251

[2]. Federal Ministry of Health (FMOH), World Health Organisation (WHO) Nigeria. Adolescent sexuality and reproductive health. Grange A, Odemwingwe T, Oyeledun B, editors. Training manual and facilitator's guide. Lagos: Fidel Enterprises, 1999; p. 1-198.

[3]. FGN . National Policy on Education. Lagos, 1990: Government printers.

[4]. S. F. Forman, and S. J. Emans, Current goals for adolescent health care. Hosp Physician. 2000;36(1):27-42

[5]. U.W. Ibor, O.A. Anjorin, A. E. Ita, M. A. Out, and T. I. Bassey, Utilization of Antenatal Care in Ibadan North Local Government Area, Oyo State, Nigeria. Trends in Medical Research, 2011; 6: 273-280.

[6]. DOI: $10.3923 / \mathrm{tmr} .2011 .273 .280$.

URL: http://scialert.net/abstract/? doi=tmr.2011.273.280

[7]. Inem, O. O. Ayankogbe, M. Obazee, M. M. Ladipo, N. E. Udonwa, and K. Odusote, Conceptual and contexual paradigm of the family as a unit of care. Nig Med Prac. 2004;45(112):9-12.

[8]. National Population Commission, Nigeria Demographic and Health Survey (NDHS), Abuja, Nigeria, 2003.

[9]. H. Stattin, and D. Magnussein, Pubertal Maturation in Female Development. Hillsdale: N. J. Erlbaum, 1990.

[10]. S. Tripovic, Risk behaviour of adolescents in the condition of transition at Gordana-Belgrade. Abstract presented at 17th World Conference of Family Doctors (WONCA); Orlando USA, 2004. 3377; 201.

[11]. K. Weyman, W. Watson, and W. Wetzel, Managing the adolescent patient in family practice. Abstract presented at: 17th World Conference of Family Doctors (WONCA), 2004. Orlando, USA. 3399;127. 